\title{
Corona Days: Quite Challenging in Many Ways
}

\author{
David Berkow ${ }^{*}$ \\ ${ }^{1}$ Department of Optometry, Berkow Optometrists, Israel \\ *Corresponding Author: David Berkow, Department of Optometry, Berkow Optometrists, Israel; \\ Email: berkowdavid@gmail.com
}

Received Date: 16-10-2020; Accepted Date: 30-10-2020; Published Date: 06-11-2020

Copyright $^{\oplus} 2020$ by Berkow D. All rights reserved. This is an open access article distributed under the terms of the Creative Commons Attribution License, which permits unrestricted use, distribution, and reproduction in any medium, provided the original author and source are credited.

\section{Editorial}

The World Health Organization (WHO) has declared that Coronavirus (COVID-19) is a pandemic that requires a combined effort worldwide, at least until a vaccine is found [1]. In December 2019, an unknown virus named Severe Acute Respiratory Syndrome Coronavirus 2 (SARS-CoV-2) or (2019-nCoV) spread in the Hubei province of China. The symptoms of the infection are like those of seasonal flu: fever, headache, shortness of breath, cough, muscle pain, tiredness and a sudden loss of taste or smell. These symptoms may appear 12-14 days after exposure to the virus [2]. It has been shown that the SARS-CoV-2 virus is found in tears and conjunctival secretions [3]. Therefore, as eye care professionals, we must be extremely careful. According to the WHO, as of the $9^{\text {th }}$ of October 2020, there were 36,361,054 confirmed cases of COVID-19 including 1,056,186 deaths. I do not think that, early in 2020, when the outbreak of the virus was confirmed, that people would have imagined the current situation and would have believed that some countries would be in their second lockdown or quickly heading there.

Having assessed the situation, the National Institutes of Health published a strategic plan for COVID-19 research, with five goals [4]:

1. Improve knowledge related to COVID-19

2. Better detect and diagnose the virus

3. Advance treatment

4. Accelerate research to improve prevention of the virus

5. Prevent and redress poor COVID-19 outcomes 
The research continues and we are still combatting the virus. Therefore, as eye care practitioners, we need to understand what is recommended, to avoid being infected by the virus when interacting with patients and, at the same time, also avoid endangering them. Ophthalmologists and optometrists are at high risk of becoming infected. In fact, it was an ophthalmologist who was the first to suspect the virus; he picked up the disease and unfortunately died [5]. The American Optometric Association has published guidelines, as have many other eye care associations, on how to take care of ourselves and our patients when delivering a comprehensive eye examination [6].

We also need to lower the level of anxiety amongst our patients. We must encourage our patients to contact us when concerned about their eye health. They may need an essential primary eye care examination, or it might be an urgent situation requiring an emergency visit. It is not for the patient to decide what the nature of the complaint is, but to consult with us. As time goes by, we are encountering more and more cases of anxiety both on the telephone and in the consulting room. The patient must be informed that we are taking every necessary precaution to ensure that our practices are as safe as possible. The guidelines published by the College of Optometrists in the United Kingdom state that infection control is very important [7]. This includes placing hand sanitizers, which are at least $60 \%$ alcohol at the front door of the practice. Each patient is requested to disinfect his or her hands on entering the practice. Disinfection of all surfaces that are touched by the patient and all staff is the next issue. This includes all examination equipment such as chairs, tables, chin rests trial frames, stationery that was touched, door handles, contact lens solutions and appliances used for contact lens insertion (e.g. suction holders, DMVs for scleral lens insertion and removal). We must also disinfect the foci-meter before use. When disinfecting surfaces, Ethanol solution of a $70 \%$ concentration has been shown to be effective. Cleaning agents containing sodium hypochloride $0.1 \%$ or $0.5 \%$ also have been shown to be effective against SARS 2-COVID-19.

It is recommended that all staff wear personal protective equipment, which include masks, gloves, aprons, and face/eye protection. Patients entering the practice should wear a facecovering or a surgical mask that covers the nose and mouth, always.

The body temperature of all persons entering the practice should be measured by using a noncontact thermometer, although this alone is not indicative to detect a COVID-19 carrier [8]. The normal human body temperature ranges between $36.5^{\circ} \mathrm{C}$ to $37^{\circ} \mathrm{C}$. If the temperature is $38^{\circ} \mathrm{C}$ or more this may indicate suspicion of a COVID-19 carrier [9].

Remember that there are three simple actions to take to enhance protecting yourself, your staff, your patients [10].

1. Wash hands

2. Cover Face

3. Make Space

Berkow D | Volume 1; Issue 1 (2020) | JOAR-1(1)-002 | Editorial

Citation: Berkow D. Corona Days: Quite Challenging in Many Ways. J Ophthalmol Adv Res. 
Is there a reason for optimism? This is the question we need to ask ourselves. We can see from Wuhan that social distance and lockdown measures are effective [11].

"COVID-19 is here to stay" this is what epidemiologists worldwide say. What will determine the outcome is very much dependent on each and everyone's personal behaviour that is, practicing social distancing, employing personal protection, such as wearing a face mask or surgical mask, and maintaining hand hygiene. All this is highly important until an effective vaccine is found. The experts predict that in the winter months, there will likely be an increase in transmission. Also, in colder weather, people tend to stay indoors, where the virus transmission through droplets is a bigger risk.

"Unfortunately, there is more we don't know about the virus than we do know therefore we just going to have to live with a great deal of uncertainty". This statement was made by Richard Neher, a computational biologist at the University of Basel, Switzerland [12].

\section{References}

1. Optometry Australia Coronavirus (COVID-19)-what optometrists need to know. 2020.

2. Esakandari H, Nabi-Afjadi M, Fakkari-Afjadi J, Farahmandian N, Miresmaeili SM, Bahreini E. A comprehensive review if COVID-19 characteristics. Biol Procedures Online. 2020;22:1-10.

3. Xia J, Tong J, Liu M, Shen Y, Guo D. Evaluation of coronavirus in tears and conjunctival secretions of patients with SARS-CoV-2 infection. J Med Virol. 2020;92(6):589-94.

4. NIH- wide strategic plan for COVID-19 research. National Institutes of Health. 2020.

5. Euro Times. Coronavirus, and ophthalmology: what can ophthalmologists do to protect themselves, staff, and patients from COVID-19? 2020.

6. American Optometric Association, Covid-19 (Coronavirus) eye health care guide for patients.

7. The College of optometrist primary eye care COVID-19 pandemic guidance.

8. Tharakan S, Nomoto K, Miyashita S, Ishikawa K. Body temperature correlates with mortality in COVID-19 patients. Critical Care. 2020;298(24):1-3.

9. High temperature (fever) in adults. NHS.

10. Coronavirus (COVID-19) Government. UK.

11. The Conversation. What will the world be like after coronavirus? Four possible futures. 2020.

12. How the pandemic might play out in 2021 and beyond. Nature. 2020;584:22-5. 